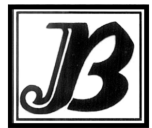

J. Bio-Sci. 29(1): 123-133, 2021 (June)

ISSN 1023-8654

http://www.banglajol.info/index.php/JBS/index

DOI: https://doi.org/10.3329/jbs.v29i0.54828

\title{
IDENTIFICATION AND ANTIBIOGRAM ASSAY OF ESCHERICHIA COLI ISOLATED FROM CHICKEN EGGS
}

\author{
MS Hossain, W Rahman, MS Ali, T Sultana and KMM Hossain* \\ Department of Veterinary and Animal Sciences, University of Rajshahi, Rajshahi-6205, Bangladesh
}

\begin{abstract}
Chicken eggs contain all the essential components such as proteins, lipids, vitamins, minerals, carbohydrates, and growth factors required by the human being. Despite of their nutritional values eggs can cause health problems through consumption of contaminated eggs with pathogenic microorganisms. Therefore, the present study was undertaken to identify Escherichia coli isolated from chicken eggs with their antibiogram assay in Rajshahi district of Bangladesh. E. coli was isolated from 180 chicken eggs collected from different areas of Rajshahi district and identified based on cultural, staining, and biochemical characteristics. Antibiogram assay of all the isolates were done by disk diffusion method. The overall prevalence of $E$. coli was $38.89 \%$ in chicken eggs of which $27.78 \%$ was on egg shells and $11.11 \%$ was in egg content. The prevalence of $E$. coli was $58.33 \%$ in commercial layer farm eggs, $41.66 \%$ in whole seller eggs, and $16.67 \%$ in retailer eggs. In antibiogram study, isolated $E$. coli showed $64.28 \%$ to $92.85 \%$ sensitivity to chloramphenicol, gentamycin, and ceftriaxone. The highest sensitivity was found to meropenem (100\%). Isolated E. coli showed resistance to ciprofloxacin, tetracycline, amoxicillin, ampicillin, and erythromycin ranging from $50 \%$ to $71.42 \%$. Judicious use of antibiotics and public awareness will help to reduce the development of antibiotic resistance.
\end{abstract}

Key words: Antibiotic resistance, Chicken eggs, E. coli, Prevalence

\section{Introduction}

Poultry industry is a promising sector for poverty elevation in Bangladesh. The Bangladesh poultry industry primarily produces chickens, although a few other species like duck, pigeon, quail, goose, turkey, and guinea fowl are available. In Bangladesh two types of chickens have been reared, one for eggs and another for meat purpose. Currently Bangladesh is producing 15.52 billion chicken eggs against the current annual demand of 17.13 billion. Globally chicken eggs are common food and consume in various dishes as a cheap source of protein which considered as the most nutritious foodstuffs for human (Pasquali et al. 2014). Egg components have been attributed diverse biological activities including antimicrobial activity, protease inhibitory action, vitamin binding properties, anticancer activity, and immunomodulatory activity. Eggs are also an important source for minerals as phosphorus and irons, and a good source of vitamins like A, D, E, $\mathrm{K}, \mathrm{B} 1, \mathrm{~B} 2, \mathrm{~B} 9, \mathrm{~B} 12$, choline and selenium. On the other hand, nutrient substances present in eggs create an excellent environment for the growth and multiplication of bacteria. Eggs can be contaminated with many bacteria such as Escherichia coli, Salmonella sp., Proteus sp., Listeria monocytogenes, Staphylococcus sp., Streptococcus sp., and Bacillus sp. (Lee et al. 2016). E. coli is one of the common microbial flora of the gastrointestinal tract of poultry and human. E. coli contaminations are more likely with a cracked eggs, dirty shells, and storage in contaminated surroundings. Contaminating egg shells increased the changes of egg contents when the shells are broken (Neira et al. 2017). Eggs contaminated with bacteria may lead to

*Author for correspondence: mozaffor@ru.ac.bd 
transmission of pathogens which associated with food-borne illness to consumers has already been established (Osimani et al. 2016, Chousalkar et al. 2018). Although most of the E. coli strains are harmless, some can cause food poisoning and diarrhea especially in elderly, infants, and those with impaired immune systems (Begum et al. 2014). Antibiotics can lead to the emergence and dissemination of resistant $E$. coli which can then be passed into human via eggs or direct contact with chickens. The emergence of antibiotic resistance in bacteria has become a serious problem worldwide. Antibiotic resistance is increasing day by day and become a public health hazard globally (Ferri et al. 2017). In Bangladesh, antibiotics are used as growth promoters as well as to control infectious poultry diseases (Hasan et al. 2014). This misuse or overuse of antibiotics in the poultry industry results the development of an increasing number of antibiotic resistant $E$. coli (Islam et al. 2018). So, identification of $E$. coli from chicken eggs and determination of their antibiotic sensitivity patterns is very much essential for the proper treatment and control purposes. The present study was therefore conducted to determine the prevalence of $E$. coli in chicken eggs in Rajshahi district and antimicrobial sensitivity assay of this bacterium that has public health significance.

\section{Materials and Methods}

The whole research work was conducted in the Microbiology Laboratory, Department of Veterinary and Animal Sciences, University of Rajshahi, Rajshahi-6205, Bangladesh.

\section{Sample collection}

A total of 180 chicken egg samples were aseptically collected from randomly selected commercial layer farms, whole sellers, and retail outlets (small shops and roadside vendors). Out of 180 egg samples, 60 eggs were collected from commercial layer farms, 60 from whole sellers, and 60 from retailers. Among these, 60 were brown shelled, 60 were white shelled, and 60 were indigenous chicken eggs.

\section{Samples preparation}

Every 5 eggs represented as one composite sample (Adesiyun et al. 2007, El-kholy et al. 2014). For egg shells, a pool of five eggs was used and one sterile swab was moistened with sterile saline and was applied on the surface of each egg. Each swab applied on five egg shells was submerged in $6 \mathrm{ml}$ of sterile saline as 'shell wash' (Adesiyun et al. 2007). The shell wash was mixed with a mini vortex and inoculated into different culture media. After that, the egg shells were sterilized by swabbed with $70 \%$ ethyl alcohol, flamed, and broken with a sterile forceps from the broad ends, and yolk and albumen of five eggs were pooled. The contents thoroughly mixed for nearly one minute using a blender and mixer was used to inoculate into different culture media.

\section{Isolation and identification of $E$. coli}

After enrichment in nutrient broth, a loopful of enriched culture was taken on a sterile glass slide and Gram's staining was performed for morphology study. Then the broth culture of bacteria was inoculated on nutrient agar by streak plate technique and inoculated at $37^{\circ} \mathrm{C}$ for 24 hours for the development of colonies. The colony on primary culture was repeatedly sub-cultured on different selective culture media (EMB agar, MacConkey agar and blood agar) by the streak plate technique until the pure culture with homogenous colonies was obtained. Identification of $E$. coli was done through a series of biochemical tests.

\section{Colony morphology}

The colony morphology of the isolated E. coli was studied as mentioned by Merchant and Packer (1967). Colony morphology such as shape, size, surface texture, edge and elevation, color, and opacity developed after 24 hour of incubation were carefully studied and recorded. 


\section{Gram's staining}

Gram's staining was performed according to the method described by Cheesbrough (1985). In brief, a small colony was picked up with a bacteriological loop, smeared on separate glass slides and fixed by gently heating. Crystal violet was applied on each smear to stain for two minutes and washed with running tap water. Few drops of Gram's iodine was added as mordent for one minute and again washed with running tap water. Acetone alcohol was added for a few seconds as a decolouring agent. After washing with water, safranin was added as a counter stain and allowed to stain for two minutes. The slides were washed with water, blotted and dried in air, and examined under light microscope with high power objective (100X) using immersion oil.

\section{Biochemical studies for the identification of isolated $E$. coli}

Pure culture of $E$. coli was subjected to different biochemical tests like sugar fermentation test (with five basic sugars for the production of acid with or without $\mathrm{H}_{2} \mathrm{~S}$ gas), catalase test, indole test, MR test, VP test, and TSI agar slant reaction. Standard methods were followed to conduct these tests and interpretation (Cowan 1985).

\section{Antibiogram assay}

The disk diffusion method (Bauer et al. 1966, Jorgensen and Turnidge 2015) was used to test the susceptibility of the $E$. coli isolates. In brief, pure colonies of the $E$. coli isolates were separately inoculated in nutrient broth and incubated at $37^{\circ} \mathrm{C}$ for overnight. Then $100 \mu \mathrm{l}$ of broth culture was taken and placed on Mueller Hinton agar plate and spread evenly with a sterile glass rod spreader. The antibiotic disks were placed on the surface of the plates keeping about $1 \mathrm{~cm}$ apart. After 18 to 20 hours of incubation at $37^{\circ} \mathrm{C}$, each plate was examined. The susceptibility test of the $E$. coli was done against ten antibiotic disks namely, gentamycin, ciprofloxacin, erythromycin, doxycycline, chloramphenicol, tetracycline, amoxicillin, ampicillin, ceftriaxone, and meropenem. The susceptibility zones were measured and interpreted according to the Clinical and Laboratory Standards Institute (CLSI 2017).

Table 1. Zone diameter interpretative standards for antimicrobial resistance

\begin{tabular}{lcccc}
\hline & $\begin{array}{c}\text { Disk concentration } \\
(\mu \mathrm{g} / \mathrm{disk})\end{array}$ & \multicolumn{3}{c}{$\begin{array}{c}\text { Interpretation of results } \\
\text { (zone diameter in mm) }\end{array}$} \\
\cline { 3 - 5 } Name of used antibiotics & & $\mathrm{R}$ & $\mathrm{I}$ & $\mathrm{S}$ \\
\hline Gentamycin & 10 & $\leq 12$ & $13-14$ & $\geq 15$ \\
Tetracycline & 30 & $\leq 11$ & $12-14$ & $\geq 15$ \\
Ampicillin & 25 & $\leq 13$ & $14-16$ & $\geq 17$ \\
Amoxycillin & 30 & $\leq 13$ & $14-17$ & $\geq 18$ \\
Ciprofloxacin & 5 & $\leq 15$ & $16-20$ & $\geq 21$ \\
Ceftriaxone & 30 & $\leq 13$ & $14-20$ & $\geq 21$ \\
Doxycycline & 30 & $\leq 10$ & $11-13$ & $\geq 14$ \\
Erythromycin & 15 & $\leq 10$ & $11-15$ & $\geq 16$ \\
Chloramphenicol & 30 & $\leq 12$ & $13-17$ & $\geq 18$ \\
Meropenem & 10 & $\leq 19$ & $20-22$ & $\geq 23$ \\
\hline
\end{tabular}

$\mu \mathrm{g}=$ Microgram, $\mathrm{mm}=$ Millimeter. $\mathrm{S}=$ Sensitive $\mathrm{I}=$ Intermediate sensitive, $\mathrm{R}=$ Resistant,$\geq=$ Greater than or equal to, and $\leq=$ Less than or equal to. 


\section{Results}

\section{Cultural characteristics}

The growth of $E$. coli on nutrient agar was indicated by the development of smooth, circular, white to grayish white colonies and on EMB by the development of smooth, circular, greenish black color colonies with metallic sheen (Fig. 1). The growth of $E$. coli on MacConkey agar was indicated by the development of bright pink colored colonies and on blood agar by the development of colorless colonies without hemolysis (Table 2).

\section{Staining characteristics}

The staining characteristics of the isolated E. coli were determined by Gram's staining technique. The microscopic examination of Gram's stained smears of $E$. coli revealed Gram's negative, pink colored, small rod shaped appearance, arranged in single or paired (Fig. 2 and Table 2).

Table 2. Morphology and cultural characteristics of isolated E. coli on different agar media

\begin{tabular}{lllll}
\hline \multicolumn{1}{c}{ Cultural characteristics of E. coli on different agar media } & \multirow{2}{*}{ Staining characteristics } \\
\cline { 1 - 3 } \multicolumn{1}{c}{ Nutrient agar } & MacConkey agar & \multicolumn{2}{c}{ EMB agar } & \multicolumn{2}{c}{ Blood agar } & \\
\cline { 1 - 1 } $\begin{array}{l}\text { Smooth, circular, } \\
\text { clear, moist, } \\
\text { white to grayish } \\
\text { white colonies }\end{array}$ & $\begin{array}{l}\text { Bright pink colored, } \\
\text { transparent, smooth, } \\
\text { raised colonies }\end{array}$ & $\begin{array}{l}\text { Greenish black } \\
\text { colonies with } \\
\text { metallic sheen }\end{array}$ & $\begin{array}{l}\text { Colorless } \\
\text { colonies without } \\
\text { hemolysis }\end{array}$ & $\begin{array}{l}\text { Gram's negative, small } \\
\text { rod shaped } \\
\text { appearance, arranged } \\
\text { in single or paired }\end{array}$ \\
\hline
\end{tabular}

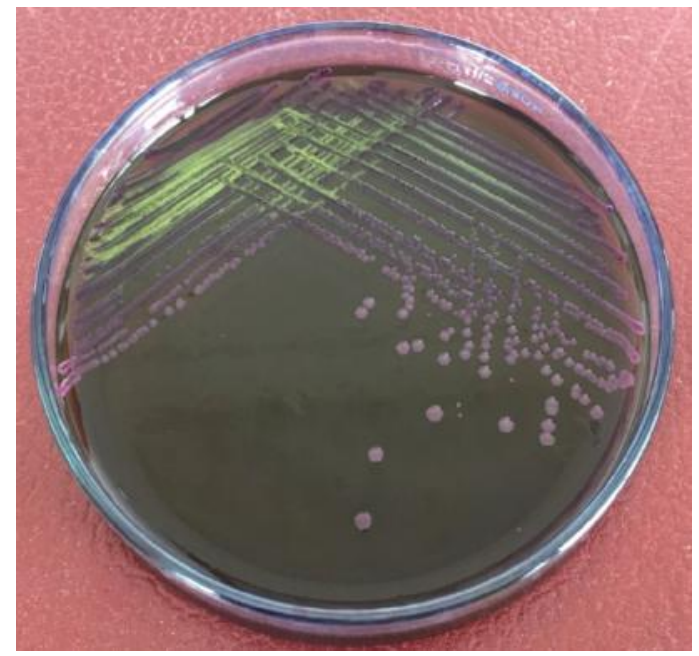

Fig. 1. Growth of E. coli on EMB agar (greenishblack colonies with metallic sheen).

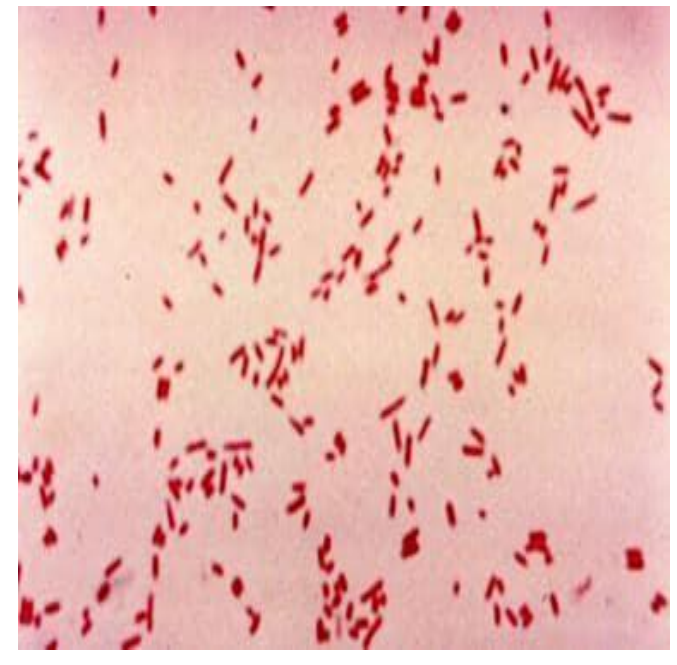

Fig. 2. Gram's stained E. coli (Gram's negative, small rod shaped appearance, arranged in single or paired under a light microscope $(100 X))$ 


\section{Biochemical properties}

Isolated E. coli fermented dextrose, lactose, sucrose, maltose, and mannitol with the production of acid and gas in sugar fermentation test (Fig. 3). Isolated E. coli showed positive results in catalase test, indole test, and MR test but showed negative result in VP test. Isolated E. coli produced acidic slant and acidic butt (yellow slant and yellow butt) with gas production in TSI agar slant reaction (Table 3).

Table 3. Biochemical properties of isolated $E$. coli

\begin{tabular}{lcccc}
\hline Tests & Used sugars & Acid production & Gas production & Results \\
\hline Fermentation & Dextrose & + & + & + \\
reaction with five & Maltose & + & + & + \\
basic sugars & Lactose & + & + & + \\
& Sucrose & + & + & + \\
& Mannitol & + & + & + \\
Indole test & & - & + \\
Catalase test & & - & + \\
MR test & & - & + \\
VP test & \multicolumn{4}{c}{} \\
TSI agar slant & Acidic slant and acidic butt (yellow slant and yellow butt) with \\
reaction & gas production \\
\hline
\end{tabular}

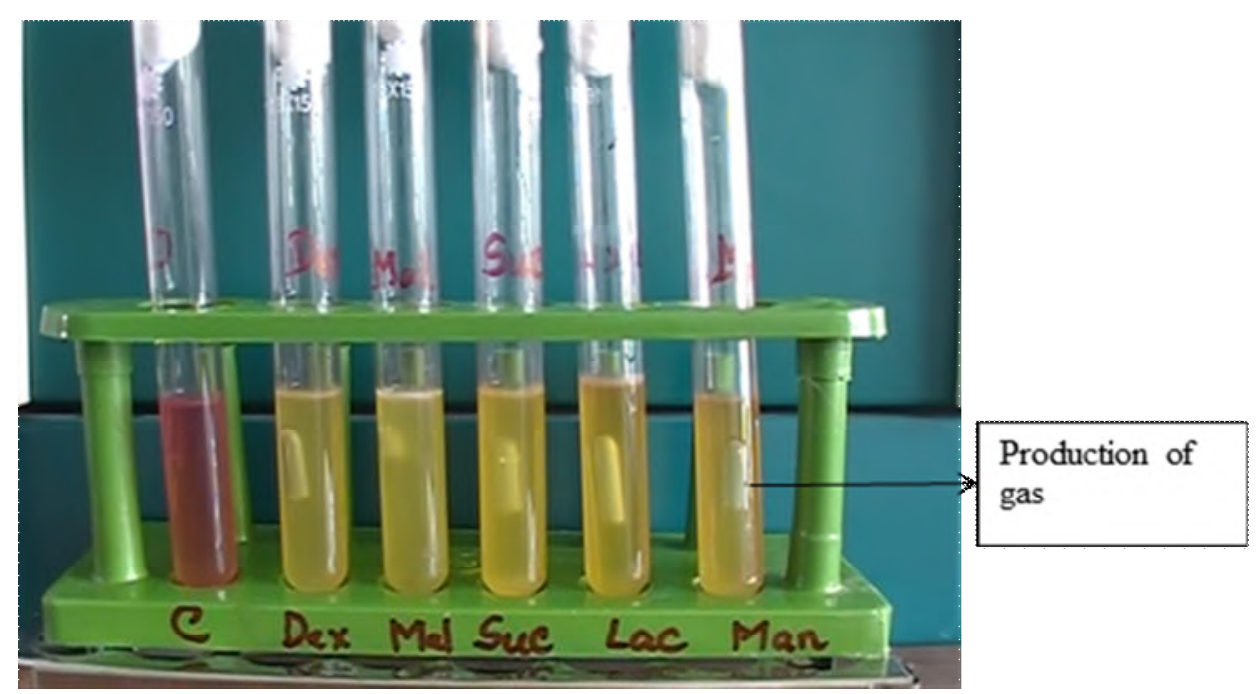

Fig. 3. Fermentation activity of isolated $E$. coli with five basic sugars (fermented dextrose, lactose, sucrose, maltose, and mannitol with the production of acid and gas). 


\section{Prevalence of $E$. coli in chicken eggs in Rajshahi district}

The overall prevalence of $E$. coli was $38.89 \%$ in chicken eggs in Rajshahi district of Bangladesh of which $27.78 \%$ was on egg shells and $11.11 \%$ was in egg contents (Table 4 and Fig. 4). The prevalence of $E$. coli was $58.33 \%$ in selected commercial layer farm eggs, $41.67 \%$ in whole seller eggs, and $16.67 \%$ in retailer eggs (Table 4 and Fig. 4).

Table 4. Prevalence of $E$. coli in chicken eggs in Rajshahi district

\begin{tabular}{lcccc}
\hline $\begin{array}{l}\text { Source of chicken } \\
\text { eggs }\end{array}$ & $\begin{array}{c}\text { No. of } \\
\text { samples } \\
\text { tested* }\end{array}$ & $\begin{array}{c}\text { Prevalence of } E \text {. } \\
\text { coli on egg shells } \\
(\%)\end{array}$ & $\begin{array}{c}\text { Prevalence of } E \text {. coli } \\
\text { in egg contents (\%) }\end{array}$ & $\begin{array}{c}\text { Overall prevalence } \\
\text { of } E \text {. coli (\%) }\end{array}$ \\
\hline $\begin{array}{l}\text { Commercial layer } \\
\text { farms }\end{array}$ & 12 & $5(41.66 \%)$ & $2(16.67 \%)$ & $7(58.33 \%)$ \\
Whole sellers & 12 & $3(25.00 \%)$ & $2(16.67 \%)$ & $5(41.66 \%)$ \\
Retailers & 12 & $2(16.67 \%)$ & $0 \%$ & $2(16.67 \%)$ \\
Total & 36 & $10(27.78 \%)$ & $4(11.11 \%)$ & $14(38.89 \%)$ \\
\hline
\end{tabular}

*= Pooled egg samples, every 5 eggs represented as one a composite sample.

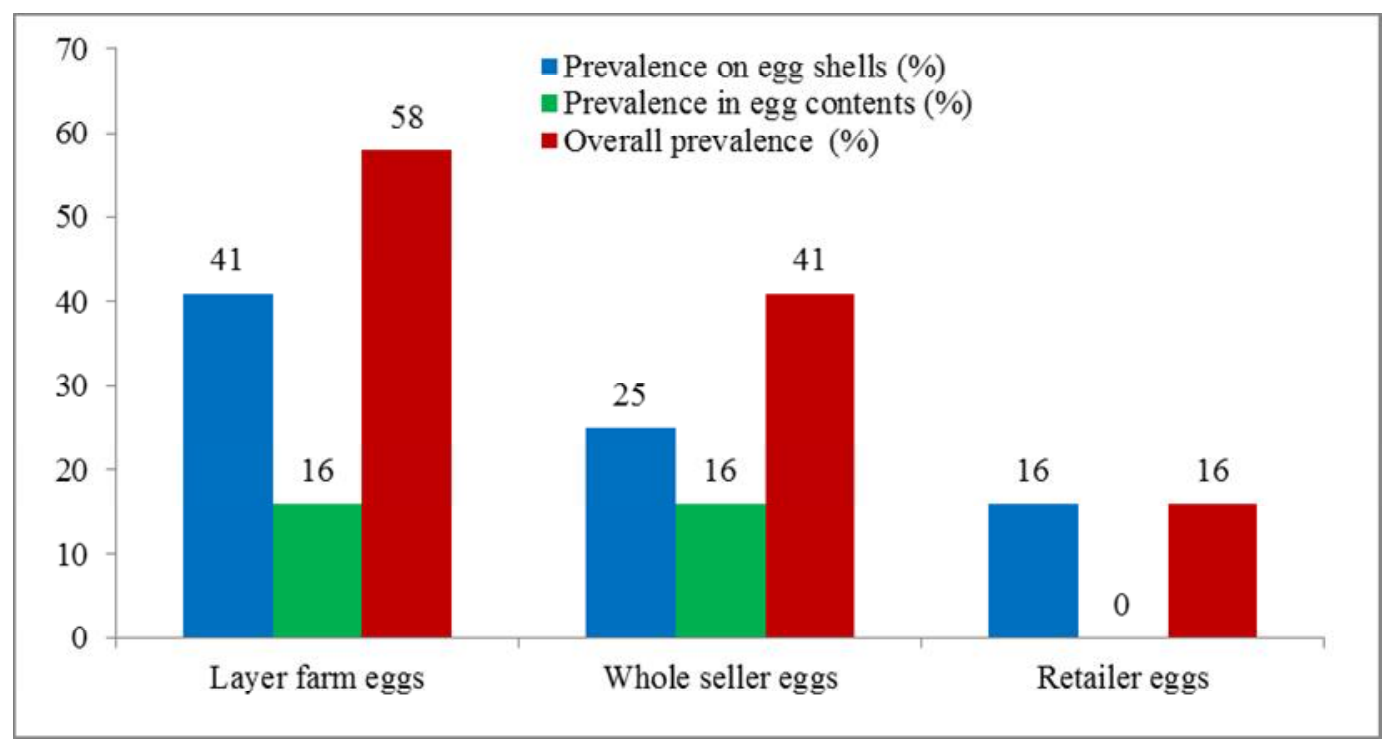

Fig. 4. Prevalence of $E$. coli in chicken eggs in Rajshahi district.

The prevalence of $E$. coli was $41.67 \%$ in indigenous chicken eggs, $25.00 \%$ in brown shell chicken eggs, and $50.00 \%$ in white shell chicken eggs (Table 5 and Fig. 5). 
Table 5. Prevalence of $E$. coli in different type chicken eggs in Rajshahi district

\begin{tabular}{lcccc}
\hline Type of chicken eggs & $\begin{array}{c}\text { No. of } \\
\text { samples } \\
\text { tested }\end{array}$ & $\begin{array}{c}\text { Prevalence of } E \text {. } \\
\text { coli on egg } \\
\text { shells (\%) }\end{array}$ & $\begin{array}{c}\text { Prevalence of } E . \\
\text { coli in egg contents } \\
(\%)\end{array}$ & $\begin{array}{c}\text { Overall prevalence } \\
\text { of } \\
\text { E. coli (\%) }\end{array}$ \\
\hline Indigenous chicken eggs & 12 & $4(33.33 \%)$ & $1(8.33 \%)$ & $5(41.67 \%)$ \\
Brown shell chicken eggs & 12 & $2(16.67 \%)$ & $1(8.33 \%)$ & $3(25.00 \%)$ \\
White shell chicken eggs & 12 & $4(33.33 \%)$ & $2(16.67 \%)$ & $6(50.00 \%)$ \\
Total & 36 & $10(27.78 \%)$ & $4(11.11 \%)$ & $14(38.89 \%)$ \\
\hline
\end{tabular}

*= Pooled egg samples, every 5 eggs represented as one composite sample.

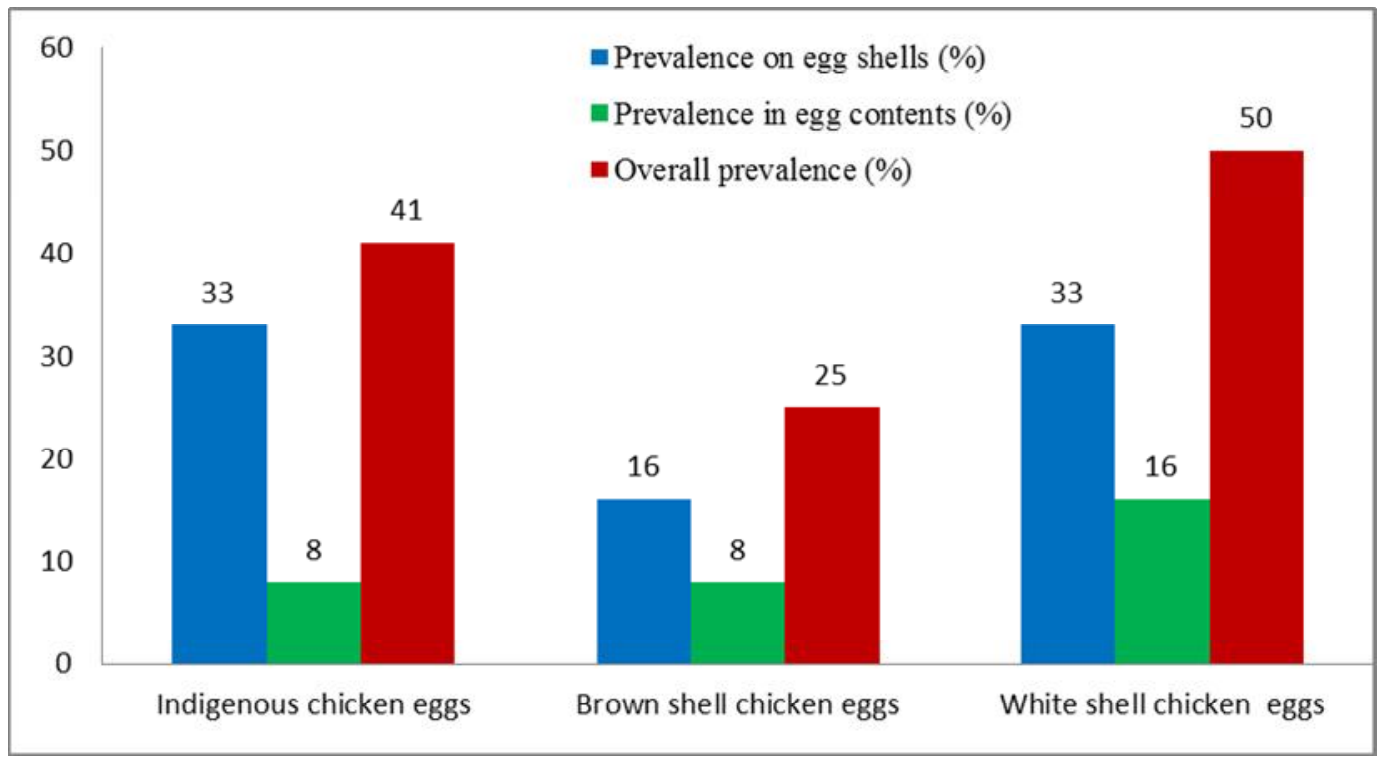

Fig. 5. Prevalence of $E$. coli in different type chicken eggs in Rajshahi district.

\section{Antibiotic sensitivity and resistant patterns of isolated $E$. coli}

The results of antibiotic sensitivity patterns of the isolated $E$. coli showed $71.42 \%, 71.42 \%, 64.28 \%, 57.14 \%$, $50.00 \%, 35.71 \%$, and $21.42 \%$ resistant to erythromycin, ampicillin, amoxicillin, tetracycline, ciprofloxacin, doxycycline, and chloramphenicol, respectively (Table 6 and Fig. 7). In sensitivity assay, isolated E. coli showed $100 \%, 92.85 \%, 78.57 \%, 64.28 \%, 35.71 \%, 21.42 \%, 14.29 \%, 14.29 \%$, and $14.29 \%$ sensitive to meropenem, ceftriaxone, gentamycin, chloramphenicol, ciprofloxacin, amoxicillin, doxycycline, ampicillin, and tetracycline, respectively (Table 6 and Fig. 7). The isolates also showed intermediate sensitive to doxycycline (50\%), erythromycin (28.57\%), tetracycline (28.57\%), gentamycin (21.42\%), ciprofloxacin (14.29\%), chloramphenicol (14.29\%), amoxicillin (14.29\%), ampicillin (14.29\%), and ceftriaxone (7.14\%). 


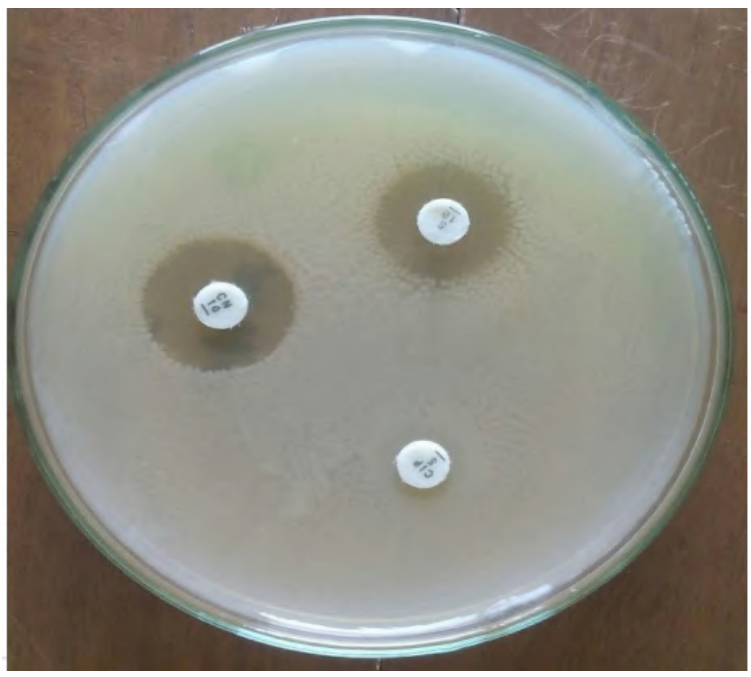

Fig. 6. Antibiotic sensitivity and resistant patterns of isolated E. coli on Mueller Hinton agar.

Table 6. Antibiotic sensitivity and resistant patterns of isolated $E$. coli

\begin{tabular}{lccc}
\hline \multirow{2}{*}{ Name of used antibiotics } & \multicolumn{3}{c}{ Sensitivity patterns $(\mathrm{n}=14)$} \\
\cline { 2 - 4 } & Sensitive (\%) & Intermediate sensitive (\%) & Resistant (\%) \\
\hline Gentamycin & 78.57 & 21.42 & 0.0 \\
Ciprofloxacin & 35.71 & 14.29 & 50.0 \\
Erythromycin & 0.0 & 28.57 & 71.42 \\
Doxycycline & 14.29 & 50.0 & 35.71 \\
Chloramphenicol & 64.28 & 14.29 & 21.42 \\
Tetracycline & 14.29 & 28.57 & 57.14 \\
Amoxicillin & 21.42 & 14.29 & 64.28 \\
Ampicillin & 14.29 & 14.29 & 71.42 \\
Ceftriaxone & 92.85 & 7.14 & 0.0 \\
Meropenem & 100.0 & 0.0 & 0.0 \\
\hline
\end{tabular}




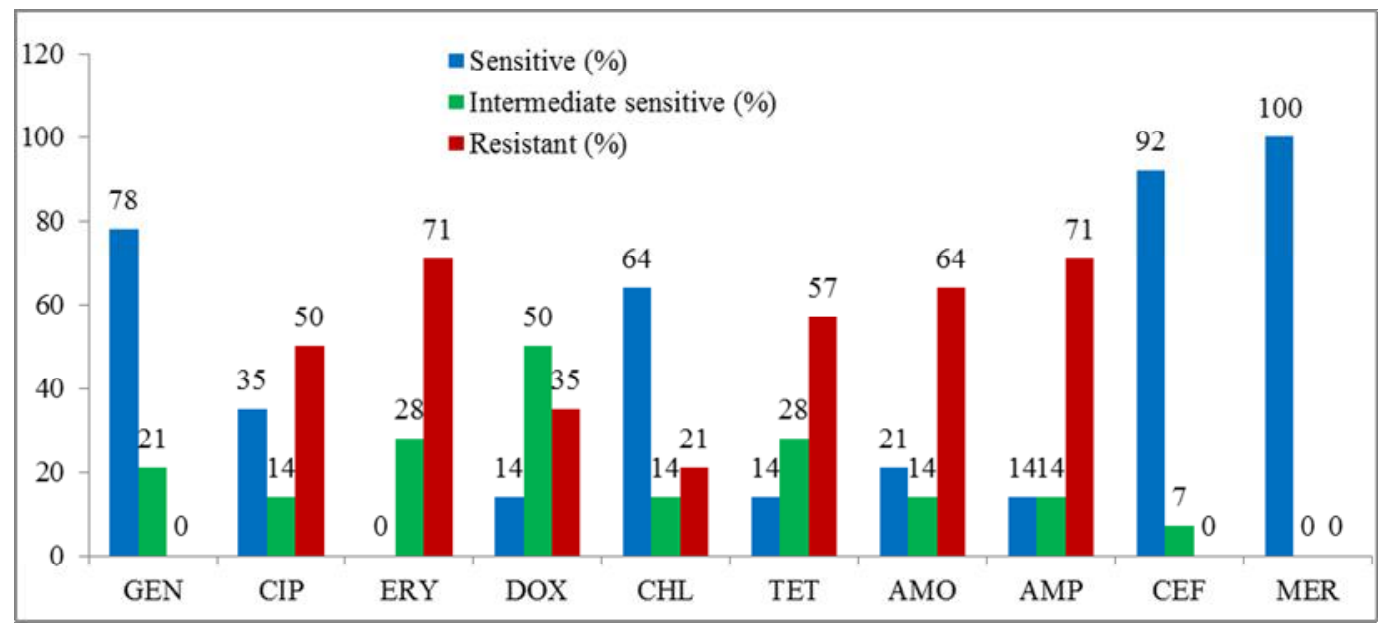

Fig. 7. Antibiotic sensitivity and resistant patterns of isolated $E$. coli $(\mathrm{GEN}=$ Gentamycin, $\mathrm{CIP}=$ Ciprofloxacin, $\mathrm{ERY}=$ Erythromycin, $\mathrm{DOX}=$ Doxycycline, $\mathrm{CHL}=$ Chloramphenicol, $\mathrm{TET}=$ Tetracycline, $\mathrm{AMO}=$ Amoxicillin, $\mathrm{AMP}=$ Ampicillin, $\mathrm{CEF}=$ Ceftriaxone, and MER = Meropenem $)$.

\section{Discussion}

The prevalence of $E$. coli was $38.89 \%$ in chicken eggs in the present study. This finding is in agreement with the findings of Islam et al. (2018) who reported that $34.64 \%$ chicken eggs were contaminated with $E$. coli in Dhaka city of Bangladesh. Our finding is lower than the finding of Gole et al. (2013) who reported that the prevalence of $E$. coli was $60.78 \%$ in chicken eggs in Australia. In the current study, the prevalence $E$. coli was $58.33 \%$ in commercial layer farm eggs. Similarly, Adesiyun et al. (2005) reported that $58.7 \%$ chicken eggs were contaminated with E. coli in farms in Trinidad. However, Akond et al. (2009) reported that $42 \%$ chicken eggs surfaces were contaminated with $E$. coli in poultry and poultry farms environments in Bangladesh. The prevalence of $E$. coli was $27.78 \%$ on chicken egg shells in our study. Similar reports were published previously by Adesiyun et al. (2005) and Eman et al. (2015). Adesiyun et al. (2005) reported that 28.3\% chicken egg shells were contaminated with E. coli in Trinidad. Eman et al. (2015) stated that $28.58 \%$ chicken egg shells were $E$. coli contaminated in Egypt. The prevalence of $E$. coli in egg contents was $11.11 \%$ in the present study. Similarly, El-kholy et al. (2014) reported that the prevalence of $E$. coli was $11.76 \%$ in chicken egg contents in Beni-suef city, Egypt. However, our finding is higher than the findings of Adesiyun et al. (2005), Sabrinath et al. (2009), and Safaei et al. (2011). Adesiyun et al. (2005) reported that 3.8\% chicken egg contents was positive for $E$. coli. Sabrinath et al. (2009) reported that the prevalence of $E$. coli was $13.3 \%$ and $45.8 \%$ in chicken egg contents collected from large farms and small farms, respectively in Grenada. Safaei et al. (2011) reported that $19 \%$ chicken egg contents were contaminated with $E$. coli in Shahrekord, Iran. In the current study, the results of antibiotic sensitivity patterns of the isolated $E$. coli showed $71.42 \%, 71.42 \%, 64.28 \%, 57.14 \%, 50.00 \%, 35.71 \%$, and $21.42 \%$ resistant to erythromycin, ampicillin, amoxicillin, tetracycline, ciprofloxacin, doxycycline, and chloramphenicol, respectively. The isolated E. coli was also showed 100\%, 92.85\%, 78.57\%, 64.28\%, 35.71\%, 21.42\%, 14.29\%, $14.29 \%$, and $14.29 \%$ sensitive to meropenem, ceftriaxone, gentamycin, chloramphenicol, ciprofloxacin, amoxicillin, doxycycline, ampicillin, and tetracycline, respectively. The antibiotic sensitivity and resistant patterns of $E$. coli are consistent with previous reports of Akond et al. (2009), Islam et al. (2018), Islam et al. (2008), Jain and Yadav (2017), Eid et al. (2015), and Adesiyun et al. (2007). Akond et al. (2009) reported that E. coli isolated from chicken eggs was resistant to erythromycin (64\%), ampicillin (58\%), tetracycline (52\%), 
ciprofloxacin (82\%), and chloramphenicol (20\%). Islam et al. (2018) stated that $100 \%, 88.89 \%$ and $77.78 \%$ of E. coli isolates was resistant to tetracycline, amoxicillin, and ampicillin, respectively prevalent in chicken eggs. Islam et al. (2008) reported that $66-100 \%$ E. coli strains isolated from chicken eggs showed resistant to tetracycline, erythromycin, and chloramphenicol in Bangladesh. Jain and Yadav (2017) reported that $E$. coli isolated from chicken eggs were 100\% sensitive to gentamicin and ciprofloxacin. Eid et al. (2015) reported that $94 \%$ of $E$. coli isolated from backyard chicken eggs was resistant to five and more antimicrobial agents. Adesiyun et al. (2007) reported that E. coli isolated from chicken eggs was resistant to tetracycline in $35.9 \%$ and resistant to gentamicin in $11.5 \%$ but $46.6 \%$ of isolates were resistant to three or more antimicrobial agents. The variation in the sensitivity and resistant patterns among different studies may due to indiscriminate use of antibiotics.

\section{Conclusion}

The overall prevalence of $E$. coli was $38.89 \%$ in chicken eggs in Rajshahi district of Bangladesh. The isolated E. coli showed $71.42 \%, 71.42 \%, 64.28 \%, 57.14 \%, 50.00 \%, 35.71 \%$, and $21.42 \%$ resistant to erythromycin, ampicillin, amoxicillin, tetracycline, ciprofloxacin, doxycycline, and chloramphenicol, respectively. In the context of this study, the prevalence of $E$. coli in chicken eggs and their antibiotic resistance is obviously significant. It could be concluded that the antibiotic resistant $E$. coli from chicken eggs may pose a public health hazard to consumers. Thus, the use of antibiotics in the poultry industry should be limited to reduce the development of antibiotic resistant $E$. coli strain.

\section{Acknowledgements}

This research work was financially supported by the University Grand Commission (UGC) of Bangladesh.

\section{References}

Akond MA, Alam S, Hassan SMR and Shirin M (2009). Antibiotic resistance of Escherichia coli isolated from poultry and poultry environment of Bangladesh. International Journal of Food Safety, 11: 19-23.

Adesiyun A, Offiah N, Seepersadsingh N, Rodrigo S, Lashley V, Musai L and Georges K (2005). Microbial health risk was posed by table eggs in Trinidad. Epidemiology and Infection, 133: 1049-1056.

Adesiyun A, Ofah N, Seepersadsingh N, Rodrigo S, Lashley V and Musai L (2007). Antimicrobial resistance of Salmonella spp. and Escherichia coli isolated from table eggs. Food Control, 18 (4): 306-311.

Bauer AW, Kirby WMM, Sherris JC and Turck M (1966). Antibiotic susceptibility testing by a standardized single disk method. American Journal of Clinical Pathology, 45(4): 493-496.

Begum S, Hazarika GC and Rajkhowa S (2014). Prevalence of Escherichia coli from pigs and cattle. Journal of Animal Health and Production, 2(3): 38-39.

Clinical and Laboratory Standards Institute (CLSI) (2017). Performance Standards for Antimicrobial Susceptibility Testing. 26 $6^{\text {th }}$ Edition. CLSI supplement M100S. Wayne, Pennsylvania, USA.

Cheesbrough M (1985). Medical Laboratory Manual for Tropical Countries. 1st Edition. In: Microbiolgy, Doddington, UK.

Chousalkar K, Gast R, Martelli F and Pande V (2018). Review of egg related salmonellosis and reduction strategies in United States, Australia, United Kingdom and New Zealand. Critical Reviews in Microbiology, 44(3): 290-303.

Cowan ST (1985). Cowan and Steel's Manual for Identification of Medial Bacteria. $2^{\text {nd }}$ Edition, Cambridge University Press, Cambridge, London.

El-Kholy AM, Hassan GM and Dalia MA (2014). Microbiological quality of poultry farm table eggs in beni-suef city, Egypt. Assiut Veterinary Medical Journal, 60(142): 10-13. 
Eman F, Abdel-Latif and Saad MF (2015). Microbiological profile of leaking chicken table eggs. International Journal of Science and Nature, 6(1): 51-55.

Eid S, Nasef SA and Erfan AM (2015). Multidrug resistant bacterial pathogens in eggs collected from backyard chickens. Assiut Veterinary Medical Journal, 61(144): 87-103.

Ferri M, Ranucci E, Romagnoli P and Giaccone V (2017). Antimicrobial resistance: a global emerging threat to public health systems. Critical Reviews in Food Science and Nutrition, 57: 2857-2876.

Gole VC, Chousalkar KK and Roberts JR (2013). Survey of Enterobacteriaceae contamination of table eggs collected from layer flocks in Australia. International Journal of Food Microbiology, 164(2-7): 161-165.

Hassan MM, Amin KB, Ahaduzzaman M, Alam M, Faruk MSA and Uddin I (2014). Antimicrobial resistance pattern against $E$. coli and Salmonella in layer poultry. Research Journal for Veterinary Practitioners, 2(2): 30-35.

Islam MJ, Sultana S, Das KK, Sharmin N and Hassan MN (2008). Isolation of plasmid-mediated multidrug resistant Escherichia coli from poultry. International Journal of Sustainable Crop Production, 3(5): 46-50.

Islam M, Sabrin MS, Kabir MHB and Aftabuzzaman M (2018). Antibiotic sensitivity and resistant pattern of bacteria isolated from table eggs of commercial layers considering food safety issue. Asian Journal of Medical and Biological Research, 4(4): 323-329.

Jorgensen JH and Turnidge JD (2015). Susceptibility test methods: dilution and disk diffusion methods, Manual of clinical microbiology. $11^{\text {th }}$ Edition. American Society for Microbiology, Washington, DC.

Jain AKR and Yadav R (2017). Study of antibiotic resistance in bacteria isolated from table egg. International Journal of Pharmacology and Biological Sciences, 8: 668-674.

Lee M, Seo DJ, Jeon SB, Ok HE, Jung H, Choi C and Chun HS (2016). Detection of foodborne pathogens and mycotoxins in eggs and chicken feeds from farms to retail markets. Korean Journal for Food Science and Animal Resources, 36: 463-468.

Merchant IA and Packer RA (1967). Veterinary Bacteriology and Virology. $7^{\text {th }}$ Edition. The lowa University Press, USA.

Neira C, Laca A, Laca A and Diaz M (2017). Microbial diversity on commercial eggs as affected by the production system. A first approach using PGM. International Journal of Food Microbiology, 262: 3-7.

Osimani A, Aquilanti L and Clementi F (2016). Salmonellosis associated with mass catering: A survey of European Union cases over a 15-year period. Epidemiology and Infection, 144(14): 3000-3012.

Pasquali F, Decesaro A, Valero A, Olsen JE and Manfreda G (2014). Improvement of sampling plan for Salmonella detection in pooled table eggs by use of real-time PCR. International Journal of Food Microbiology, 184: 31-34.

Safaei HG, Jalali M, Hosseini A, Narimani T, Sharifzadeh A and Raheimi E (2011). The prevalence of bacterial contamination of table eggs from retails markets by Salmonella spp., Listeria monocytogenes, Campylobacter jejuni and Escherichia coli in Shahrekord, Iran. Jundishapur Journal of Microbiology, 4(4): 249-253.

Sabarinath A, Guillaume V, Guillaume B, Mathew V, De Allie C and Sharma RN (2009). Bacterial contamination of commercial chicken eggs in Grenada, West Indies. West Indian Veterinary Journal, 9(2): 4-7. 